intervene therapeutically with children exposed to disasters affecting the adults in their world.

DORA BLACK

Consultant Child Psychiatrist,

Edgware General Hospital,

Middlesex HA8 OAD

1 Clarke AM, Clarke ADB. Early experience, myth and evidence. London: Open Books, 1976.

${ }^{2}$ Fraser M. Children in conflict. Harmondsworth: Penguin, 1973.

${ }^{3}$ Caplan G. Opportunities for school psychologists in primary prevention of mental disorders in children. In: Lambert NM, ed. The protection and promotion of mental health in schools. Bethesda, Maryland: US Department of Health, Education and Welfare, 1965.

+ Parkes CM. Preface and postscript. In: Erikson K. In the wake of the flood. London: George Allen and Unwin, 1979.

${ }^{5} \mathrm{McWhirter} \mathrm{L}$, Trew K. Children in Northern Ireland: a lost generation ? In: Anthony EJ, Chiland C, eds. Child in his family: children in turmoil: tomorrow's parents. Vol 7. New York and Chichester: Wiley-Interscience, 1982.

\section{New prospects for luteinising hormone releasing hormone as a contraceptive and therapeutic agent}

Gonadal function is controlled by luteinising hormone (LH) and follicle-stimulating hormone (FSH) from the pituitary gland. Since the release of these hormones depends on secretion of hypothalamic luteinising hormone releasing hormone (LHRH), manipulation of this releasing factor has profound effects on the reproductive system. The synthesis of potent synithetic antagonists and agonists of LHRH has provided the key, firstly, to a new approach to contraception free of the metabolic effects of steroidal contraceptives and, secondly, to the ability to induce a "medical gonadectomy."

Use of the antagonists seems the most logical approach to blocking release of the gonadotrophins, but the development of sufficiently potent compounds for use in man has been arduous and clinical trials are only now getting under way. ${ }^{1}$ Paradoxically, it is the agonists-originally developed to treat infertility-which have produced the most dramatic inhibitory effects. For normal function, the pituitary is stimulated by pulses of LHRH released from the hypothalamus, which in turn cause pulsatile secretion of $\mathrm{LH}$, which stimulates the testis and ovary. This pattern of hormone release may be overriden by daily administration of an LHRH agonist; its prolonged biological action soon leads to a process of "down regulation" of the pituitary gonadotrophs and gonads.

Administration of an agonist can disrupt the function of both the follicle and the corpus luteum in the normal cycle, but the simplest approach to contraception is to inhibit ovulation by daily treatment with an agonist, and this has been studied in trials in macaque monkeys and in women. ${ }^{2-8}$ LHRH agonists are degraded if taken orally, and nasal sprays have been developed so that the agonist may be absorbed through the nasal mucosa.

In the normal cycle the gonadotrophins stimulate a follicle to develop and produce oestradiol. After the midcycle surge of $\mathrm{LH}$ the follicle ovulates to form a corpus luteum producing progesterone. If an agonist is taken daily, starting at the beginning of the cycle, there is an initial stimulatory phase, but continued administration of the agonist decreases the ability of the pituitary to release the large amounts of gonadotrophin necessary to cause ovulation. ${ }^{4}$ The effect on follicular development, as judged by plasma concentrations of oestradiol, varies among individuals. In about one-quarter follicular development is suppressed, while in the remainder the fluctuating oestrogen concentrations indicate maturation of a follicle which does not ovulate.

If an LHRH agonist is to be successful as a contraceptive by this approach it must maintain the secretion of oestradiol within acceptable limits. Suppression of follicular growth might be expected to cause symptoms of oestrogen deficiency, but the indications are, however, that enough oestrogen is produced to avoid this problem. ${ }^{2}{ }^{6} 7$ Indeed, in those womer in whom oestrogen is suppressed the only side effect seems to be amenorrhoea-welcome enough provided the contraceptive effect is certain. ${ }^{9}$ When oestrogen secretion is not suppressed, however, the effects of "unopposed" oestrogen on the endometrium come into question. In these circumstances women experience menstrual-type bleeds or "spotting" at regular or irregular intervals. After prolonged treatment with an agonist the endometrial activity may range from inactive to considerable proliferation, though activity tends to decrease as treatment progresses. ${ }^{356}$ One way of overcoming this problem and of irregular bleeding would be to administer progesterone to induce a withdrawal bleed-but this approach detracts from the concept of avoiding exogenous steroids.

Who would use an LHRH agonist as a contraceptive? It would not replace the steroid contraceptives when these are acceptable. But the agonists may be a suitable alternative for women who stop the contraceptive pill because of the side effects they experience and those over the age of 35, who run an increased risk from continuing with steroids.

Another important possibility is that agonists may have therapeutic as well as contraceptive actions in women with menstrual disorders. For example, a lowering of the oestrogen output combined with absent progesterone peaks may help to alleviate some symptoms of the premenstrual syndrome. Since agonists can induce amenorrhoea with an inactive endometrium in some women, they may be suitable contraceptives in women with menorrhagia or endometriosis-conditions which tend to become more severe towards the end of reproductive life, when the use of steroids is less desirable. This approach could be extended to achieve a "medical oophorectomy" by using high doses of agonist and so suppressing the production of oestrogen as well as inhibiting ovulation. ${ }^{10}$ In one pilot study, women with endometriosis appeared to benefit from this treatment but experienced "hot flushes," probably related to their low oestrogen outputs. Perhaps a dose may be found that reduces the severity of this side effect.

The same concept of medical oophorectomy is being explored in premenopausal women with breast cancer. These patients need to have their secretion of oestrogen completely suppressed, and this can be achieved by injecting amounts of agonist many times higher than that required for contraception. Preliminary results in patients with metastatic breast cancer showed significant improvement in two of four women ${ }^{11}$; and long-term trials are in progress in the United States.

Long-term treatment with LHRH agonists in men has potential as a contraceptive since it reduces the number of sperms. As with other methods which interfere with $\mathrm{LH}$ as well as FSH, however, the effect on spermatogenesis is at the expense of decreasing testosterone production, which causes loss of libido and impotence. ${ }^{12} \mathrm{~A}$ combination of agonist 
treatment with testosterone replacement is next to be investigated, but such treatment has yet to be confirmed as causing infertility. Furthermore, the dose of agonist required to interrupt reproductive function in men is much higher than for inhibiting ovulation. All in all, contraception through use of agonists is less attractive in men than in women.

When these endocrine changes are extended to treatment of cancer of the prostate, however, use of LHRH agonists holds much promise. Trials lasting up to a year have indicated that agonists can reduce testosterone concentrations far enough to achieve success similar to surgical castration..$^{13-16}$ Without doubt a method of "medical" castration would offer real advantages in treating these patients. Furthermore, treatment with agonists is without the problems of treatment with oestrogens, with their increased risk of cardiovascular disease and gynaecomastia. A combination of agonists to reduce production of testosterone and an antiandrogen may present an even more powerful two-pronged attack.

A further possibility centres on the recently discovered extrapituitary actions of LHRH, which show that the peptide can directly alter production of hormones not only by the testis, ovary, and placenta ${ }^{17}$ but also by arrhenoblastoma cells ${ }^{18}$ and chorionic gonadotrophin-secreting tumours. ${ }^{19}$ LHRH may also interfere directly with growth of secondary sex organs induced by steroids. ${ }^{20}$ If long-term exposure to LHRH agonists could be shown to have direct inhibitory actions on hormone-dependent tumours ${ }^{21}$ their potential as anticancer agents would be even greater.

The inhibitory actions of agonists may make them the method of choice in treating true precocious puberty. Treatment of 15 children for six to 14 months with daily injections of agonist resulted in decreased production of sex hormones. The size of the breasts, the testicular volume, and pubic and facial hair regressed, and menses ceased. Growth and bone age advanced at normal prepubertal rates. ${ }^{22} 23$

LHRH agonists are our brightest hope for a new approach to contraception and offer challenges for treatment of sexhormone related disorders and as a method of medical gonadectomy. Nevertheless, all regimens which interfere with the normal menstrual cycle seem to raise questions of advantages and disadvantages, benefits as well as risks, and these will take time to evaluate accurately.

\section{H M FRASER}

Research Scientist,

Medical Research Council Reproductive Biology Unit,

Centre for Reproductive Biology,

Edinburgh EH3 9EW

${ }^{1}$ Zarate A, Canales ES, Sthory I, Coy DH, Comaru-Schally AM, Schally AV. Anovulatory effect of a LHRH antagonist in women. Contraception $1981 ; \mathbf{2 4 : 3 1 5 - 2 0}$

Berquist C, Nillius SJ, Wide I. Intranasal LHRH agonist treatment for inhibition of orulation in women: clinical aspects. Clin Endocrinol ( ()$\times f)$ $1982 ; 17: 91-8$

Berquist (, Nillius SJ, Wide L, Lindgren A. Endometrial patterns in women on chronic luteinizing hormone-releasing hormone agonist treatment for contraception. Fertil Steril $1981 ; \mathbf{3 6}: 339-42$

4 Fraser HM. Effect of oestrogen on gonadotrophin release in stumptailed monkevs (Macuca arctoides treated chronically with an agonist anaiogue of luteinizing hormone releasing hormone. 7 Endocrinol $1981 ; 91: 525-30$.

Kerr-Wilson RHJ, Mackenzie L, Fraser HM. Effects of chronic LHRH agonist treatment on the endometrium and ovaries of the stumptailed macaque. Contraception $1981 ; 24: 647-55$

"Schmidt-(jollwitzer M, Hardt W, Schmidt-Gollwitzer K, Von der Ohe M, Nevinny-Stickel J. Influence of the $\mathrm{LH}-\mathrm{RH}$ analogue buserelin on cyclic ovarian function and on endometrium. A new approach to fertility control? Contraception $1981 ; 23: 18 ;-95$

Schmidt-Gollwitzer M, Hardt W, Schmidt-Gollwitzer K, Von der Ohe M The contraceptive use of buserelin, a potent L.HRH agonist: clinical and hormonal findings. In: Zatuchni G, ed. LHRH peptides as male and female contraceptia's. Philadelphia: Lippincott, 1982:199-215.
Vickery BH. Female contraceptive potential of "super" agonists of LHRH as assessed in infrahuman primates. In: Zatuchni G, ed. $L H R H$ peptides as male and female contraceptives. Philadelphia: Lippincott, 1982:109-25.

'Loudon NB, Foxwell M, Potts DM, Guild AL, Short RV. Acceptability of an oral contraceptive that reduces the frequency of menstruation: the tri-cycle pill regimen. $B r$ Med f 1977;ii:487-90.

1" Meldrum DR, Chang RJ, Lu J, Vale W, Rivier J, Judd HL. "Medical oophorectomy" using a long-acting GNRH agonist-a possible new approach to the treatment of endometriosis. $\mathcal{f}$ Clin Endocrinol Metab $1982 ; 54: 1081-3$.

1 Klijn JGM, de Jong FH. Treatment with a luteinising-hormone-releasinghormone analogue (buserelin) in premenopausal patients with metastatic breast cancer. Lancet 1982;i:1213-6.

12 Linde RB, Doelle GC, Alexander N, et al. Reversible inhibition of testicular steroidogenesis and spermatogenesis by a potent gonadotropinreleasing hormone agonist in normal man. $N$ Engl 7 Med $1981 ; 305$ : 663-7.

1: Borgmann V, Hardt W, Schmidt-Gollwitzer M, Adenauer H, Nagel R. Sustained suppression of testosterone production by the luteinisinghormone releasing-hormone agonist buserelin in patients with advanced prostate carcinoma. A new therapeutic approach ? Lancet 1982;i:1097-9.

$"$ Faure N, Labrie F, Lemay A, et al. Inhibition of serum androgen levels by chronic intranasal and subcutaneous administration of a potent luteinizing hormone-releasing hormone ( $\mathrm{LH}-\mathrm{RH})$ agonist in adult men. Fertil Steril $1982 ; 37: 416-24$

15 Tolis G, Ackman D, Stellos A, et al. Tumor growth inhibition in patients with prostatic carcinoma treated with luteinizing hormone-releasing hormone agonists. Proc Natl Acad Sci USA 1982;79:1658-62.

${ }^{16}$ Warner B, Santen RJ, Max D, et al. Successful "medical castration" with a superagonist analog of gonadotrophin releasing hormone $(\mathrm{GnRH})$ in treating prostatic carcinoma. Proceedings of the American Society of Clinical Investigation, 1982 (in press).

17 Hsueh AJW, Jones PBC. Extrapituitary actions of gonadotrophin-releasing hormone. Endocr Rev $1981 ; 2: 437-61$.

${ }^{18}$ Lamberts SWJ, Timmers JM, Oosterom R, Verleun T, Rommerts FG, de Jong FH. Testosterone secretion by cultured arrhenoblastoma cells: suppression by a luteinizing hormone-releasing hormone agonist. 7 Clin Endocrinol Metab 1982;54:450-4.

${ }^{19}$ Bützow R. Luteinizing hormone-releasing factor increases release of human chorionic gonadotrophin in isolated cell columns of normal and malignant trophoblasts. Int $\mathcal{F}$ Cancer 1982;29:9-11.

¿0 Sundaram K, Cao Y-Q, Wang N-G, Bardin CW, Rivier J, Vale W. Inhibition of the action of sex steroids by gonadotropin-releasing hormone $(\mathrm{GnRH})$ agonists: a new biological effect. Life Sci 1981;28: 83-8.

$\because$ Corbin A. From contraception to cancer: a review of the therapeutic applications of $\mathrm{LHRH}$ analogues as antitumor agents. Yale Biol Med (in press).

$\because$ Comite F, Cutler GB, Rivier J, Vale W, Loriaux DL, Cowley WF. Short-term treatment of idiopathic precocious puberty with a longacting analogue of luteinizing hormone-releasing hormone. A preliminary report. N Engl f Med $1981 ; 305: 1546-50$.

Comite F, Hench K, McNemar A, Dwyer A. LH-RH analog therapy in 15 children with true precocious puberty: effect on somatic growth and bone maturation. Abstract 293, 64th annual meeting of American Endocrine Society, San Francisco 1982

\section{Myocardial disarray revisited}

Irregular arrangement or "disarray" of myocardial fibres has been widely used as one of the morphological markers for hypertrophic cardiomyopathy..$^{1-5}$ More recently pathologists have shown that in normal hearts myocardial fibres are not in parallel alignment throughout the myocardium and that areas of irregular arrangement are present in various congenital and acquired cardiac conditions. ${ }^{67}$ These findings have cast doubt on the reliability of a morphological diagnosis of hypertrophic cardiomyopathy.

Since the first description of the pathological changes in this type of cardiomyopathy by Teare ${ }^{8}$ myocardial disarray has been interpreted in several ways. Some authorities" 